\title{
Robótica na educação não é um bicho-papão: relato de experiência na rede pública municipal
}

\author{
Aline Gonçalves de Almeida ${ }^{1}$, André Raabe ${ }^{2}$, Nayara Voigt ${ }^{3}$ \\ ${ }^{1}$ Programa de Pós Graduação em Educação - PPGE - Universidade do Vale do Itajaí \\ (UNIVALI) Rua Uruguai, 458- 88302202 Itajaí - SC - Brasil \\ ${ }^{2}$ Mestrado em Computação Aplicada - Universidade do Vale do Itajaí (UNIVALI) \\ Rua Uruguai, 458- 88302202 Itajaí - SC - Brasil \\ ${ }^{3}$ Professora Titular de Ciências da Rede Municipal de Itajaí \\ alseff@hotmail.com, raabe@univali.br, nayvoigt@yahoo.com.br
}

\begin{abstract}
Educational robotics is an innovative tool for meaningful learning that brings benefits for the acquisition of concepts in an interdisciplinary way. The objective was to verify the contribution of robotics as a methodological tool in the teaching-learning process, through workshops. A qualitative approach was used, with logbook and participant observation for data collection. It was concluded that the applied robotics in a public school brings benefits from the autonomy and protagonism until the re signification of roles of teachers and students, providing the development of skills and competences that transcend the delimitation of the school disciplines.
\end{abstract}

Resumo. A robótica educacional é uma ferramenta inovadora de aprendizagem significativa que traz beneficios para aquisição de conceitos, de forma interdisciplinar. O objetivo foi verificar a contribuição da robótica como ferramenta metodológica no processo ensino-aprendizagem, através de oficinas. Utilizou-se uma abordagem qualitativa, com diário de bordo e observação participante para coleta de dados. Concluiu-se que a robótica aplicada em uma escola pública traz beneficios desde a autonomia e protagonismo até a ressignificação de papéis de professores e alunos, proporcionando o desenvolvimento de habilidades e competências que transcendem a delimitação das disciplinas escolares.

\section{Introdução}

Desde a antiguidade, diversas tecnologias foram criadas a fim de melhorar a qualidade de vida das pessoas. Durante esse processo, os avanços tecnológicos permitiram importantes transformações em relação às indústrias, ao comércio, ao meio ambiente, às relações interpessoais e à educação, sendo coerente o aproveitamento destas ferramentas para o aprimoramento do processo de ensino-aprendizagem dos alunos. Nesse sentido, Chiofi e Oliveira (2014, p. 336) citam que no espaço escolar, a utilização de tecnologias como "ferramenta didática possibilita ao processo de ensino e aprendizagem uma aula mais dinâmica, interativa e contextualizada com a realidade dos alunos". 
VIII Congresso Brasileiro de Informática na Educação (CBIE 2019)

Anais do XXV Workshop de Informática na Escola (WIE 2019)

Segundo Papert (1994, p.193): “o desenvolvimento das melhores tecnologias de comunicação tem uma significativa contribuição a fazer para a transformação do sistema dirigido de Escola para um sistema de iniciativa", aproximando o conhecimento distante, formando comunidades de pessoas com diferentes experiências, fazendo com que apareçam novas formas de aprender. Sob esse viés, Zilli (2004) discorre que as novas tecnologias:

(...) favorecem novas formas de acesso ao saber pela navegação, à caça de informação, novos estilos de raciocínio e de conhecimento, como a simulação. Esses saberes podem ser compartilhados por um grande número de indivíduos e, portanto, aumentam o potencial da inteligência coletiva dos seres humanos, mudando as relações sociais e estabelecendo relações humanas e afetivas. (ZILLI, 2004, p.19)

Nessa perspectiva, tem-se o uso da robótica como uma ferramenta tecnológica educacional, em prol da motivação dos alunos ao trabalho em equipe, ao desenvolvimento da lógica, a ampliação dos conhecimentos relativos à programação, bem como a aplicação da teoria de maneira diferenciada e atrativa.

O termo robótica educacional não é atual, já fora datado desde a década de 1960. Seu precursor foi Seymour Papert, pesquisador do Massachusetts Institute of Technology (MIT), que desenvolveu a linguagem LOGO$^{1}$ e a metodologia do construcionismo, trazendo a ideia de uma aprendizagem informal, relacionada às experiências e ao aprender naturalmente fazendo (hands on). Segundo Raabe e Gomes (2018), a prática da robótica educacional é sustentada principalmente pelas teorias do construtivismo - o aprendiz interpreta o que está sendo ensinado, com base em suas experiências e conhecimentos - e do construcionismo - no qual o aprendiz está engajado em construir um objeto palpável e de seu interesse.

O conceito de robótica educacional a que nos referimos é o exposto por Menezes e Santos (2015):

Termo utilizado para caracterizar ambientes de aprendizagem que reúnem materiais de sucata ou kits de montagem compostos por peças diversas, motores e sensores controláveis por computador e softwares que permitam programar de alguma forma o funcionamento dos modelos montados. Em ambientes de robótica educacional, os sujeitos constroem sistemas compostos por modelos e programas que os controlam para que eles funcionem de uma determinada forma. (MENEZES E SANTOS, 2015, p.1)

Conforme Fiorio et al (2014), estudos tratam da robótica educacional em diversas atividades: robótica de baixo custo; software de programação; no deslocamento de programáveis em mapas geográficos; que proporcionam o desenvolvimento de expressão escrita, oral, motora e na organização do tempo e do espaço. Nesse sentido, a robótica educacional surge como ferramenta inovadora de aprendizagem significativa na educação formal, trazendo benefícios para a aquisição de diversos conceitos, de maneira interdisciplinar. Ela cumpre um papel transformador, abrindo um caminho de imaginação e criatividade, onde o próprio aluno tem a oportunidade de constituir seu conhecimento a partir de objetos que ele mesmo construiu.

\footnotetext{
${ }^{1}$ Por meio da Linguagem LOGO, a criança interage com o computador, através de comandos controla uma tartaruga robótica e aprende conceitos matemáticos. Disponível em: < https://sites.google.com/site/infoeducunirio/perspectivaconstrutivista/linguagem-logo $>$ Acesso em: 10/05/2019.
} 
VIII Congresso Brasileiro de Informática na Educação (CBIE 2019)

Anais do XXV Workshop de Informática na Escola (WIE 2019)

Concebemos que para uma melhor utilização das tecnologias no processo de ensino-aprendizagem, os papéis tanto do professor como do aluno necessitam de transformações, tendo em vista que a relação entre esses sujeitos passa a ser permeada mais por mediação do que instrução e mais por autonomia do que dependência. Quando o professor assume o papel de facilitador, o aluno passa a agir com protagonismo, com uma postura mais ativa e autônoma, participando de experiências diferentes, observando, resgatando conhecimentos prévios para estruturar os novos. Esta afirmação corrobora com Freire (1981), quando diz que:

O professor não é mais meramente o-que-ensina, mas alguém a quem também se ensina no diálogo com os estudantes, os quais, por sua vez, enquanto estão ensinando também aprendem. Eles se tornam conjuntamente responsáveis por um processo no qual todos crescem. (FREIRE, 1981)

Diante deste contexto, surge a questão problema da proposta de trabalho: como a implementação de oficinas de robótica educacional pode contribuir para $\mathrm{o}$ desenvolvimento integral do aluno com vistas na interdisciplinaridade? Desta forma, este artigo tem por objetivo verificar a contribuição da robótica educacional, como ferramenta metodológica, no processo ensino-aprendizagem, através da realização de oficinas no laboratório de informática, com um kit de robótica educacional.

\section{Contextualização e público-alvo}

O projeto de implementação das oficinas de robótica foi idealizado após uma formação continuada para professores, oferecida pela Secretaria Municipal de Educação de Itajaí SC e realizado durante o ano de 2016. Na oportunidade, foram capacitados professores e ofertado à escola um kit de robótica Atto Educacional ${ }^{\circledR}$, contendo dispositivos eletrônicos e mecânicos, como sensores de toque, luminosidade, som, motores, bluetooth, interface programável e peças diversas como barras roscadas, barras com furos, parafusos e rebites.

Para o delineamento das atividades, foram envolvidas profissionais da área de ciências, matemática e informática de uma escola pública do município de Itajaí. A instituição, com 543 alunos no ano de 2016, está inserida em um bairro afastado do centro do município, em uma comunidade de baixa renda, distante da residência da maioria dos alunos, os quais utilizam transporte escolar fornecido pela prefeitura para o acesso à escola. As oficinas aconteceram com 10 alunos do Ensino Fundamental II, com idades entre 12 e 14 anos.

\section{Metodologia}

A pesquisa se enquadra em uma abordagem qualitativa segundo os estudos de Lüdke e André (1986). Foram utilizados como métodos de coleta de dados os relatos dos participantes por meio de diários de bordo e a observação participante dos pesquisadores. Essa técnica é vantajosa por possibilitar um contato direto dos pesquisadores com o objeto de investigação, permitindo acompanhar as experiências diárias dos sujeitos e apreender o significado que atribuem à realidade e às suas ações (LÜDKE E ANDRÉ, 1986).

A análise dos dados coletados via diário de bordo e observação dos pesquisadores foi realizada por meio da técnica de análise de conteúdo (BARDIN, 2011). Para Bardin (2011), o termo análise de conteúdo designa: 
VIII Congresso Brasileiro de Informática na Educação (CBIE 2019)

Anais do XXV Workshop de Informática na Escola (WIE 2019)

Um conjunto de técnicas de análise das comunicações visando a obter, por procedimentos sistemáticos e objetivos de descrição do conteúdo das mensagens, indicadores (quantitativos ou não) que permitam a inferência de conhecimentos relativos às condições de produção/recepção (variáveis inferidas) destas mensagens. (Bardin, 2011, p. 47)

\subsection{Etapas metodológicas}

\subsubsection{Formação do grupo de robótica}

A escolha dos participantes foi realizada através de um desafio direcionado aos alunos interessados do Ensino Fundamental II: eles utilizaram o kit de robótica Atto Educacional ${ }^{\circledR}$ para produzir um protótipo com a temática Kizomba ${ }^{2}$. Os critérios avaliados foram a organização, a criatividade, a habilidade de pesquisa, a iniciativa, o desenvolvimento motor, a oratória, o trabalho em grupo e a responsabilidade. Após apresentarem seus protótipos a uma banca julgadora, foram selecionados dez alunos para participarem do projeto.

\subsubsection{Oficinas propostas}

Para a realização das oficinas foram propostos os desafios descritos na tabela 1 .

Tabela 1. Desafios propostos para o desenvolvimento das oficinas

\begin{tabular}{|c|c|c|}
\hline \multicolumn{3}{|c|}{ Oficinas } \\
\hline Desafios & Primeiro semestre de 2016 & Segundo semestre de 2016 \\
\hline $\mathbf{1}$ & $\begin{array}{c}\text { Sugerir um nome para o grupo } \\
\text { para votação no blog escolar. }\end{array}$ & $\begin{array}{c}\text { Desenvolvimento de protótipos que } \\
\text { interagem com a interface } \\
\text { programável do kit de robótica Atto } \\
\text { Educacional } \mathbb{R} \text {, utilizando os sensores } \\
\text { analógicos e digitais e as plataformas } \\
\text { Arduíno e Ardublock. }\end{array}$ \\
\hline $\mathbf{2}$ & $\begin{array}{c}\text { Elaborar jogos baseados em } \\
\text { esportes olímpicos ou } \\
\text { paraolímpicos e adequados aos } \\
\text { alunos dos segundos anos do } \\
\text { ensino fundamental I. }\end{array}$ & $\begin{array}{c}\text { Desenvolvimento de protótipos para a } \\
\text { aplicação dos conceitos de física e } \\
\text { realização de uma aula prática com os } \\
\text { alunos do nono ano do ensino } \\
\text { fundamental II. }\end{array}$ \\
\hline $\mathbf{3}$ & $\begin{array}{c}\text { Desenvolver objetos } \\
\text { automatizados com a utilização } \\
\text { de motores e materiais } \\
\text { alternativos. }\end{array}$ & $\begin{array}{c}\text { Visita técnica ao grupo de robótica } \\
\text { WickedBotz, da PUC de Jaraguá do } \\
\text { Sul. }\end{array}$ \\
\hline
\end{tabular}

\section{Resultados e discussões}

\subsection{Formação do grupo de robótica}

Após a divulgação das oficinas de robótica, dez alunos foram selecionados conforme o desempenho na apresentação de seus protótipos sobre o tema Kizomba, de acordo com os critérios previamente estabelecidos.

\footnotetext{
2 Evento realizado pelas escolas da Secretaria Municipal de Educação de Itajaí - SC, com trabalhos
} realizados sobre a cultura afro-brasileira. 
VIII Congresso Brasileiro de Informática na Educação (CBIE 2019)

Anais do XXV Workshop de Informática na Escola (WIE 2019)

\title{
4.2. Oficinas
}

\subsubsection{Desafios para o primeiro semestre de 2016}

- Primeiro desafio: Os nomes sugeridos foram colocados à disposição da comunidade escolar e publicados no blog da escola para votação. Após a votação, o nome escolhido pela comunidade escolar foi "Roboticando". A utilização do blog educacional facilita a visualização dos acontecimentos e saberes desenvolvidos na escola, sendo uma ferramenta importante de aproximação dos pais às atividades realizadas. Araújo (2009) aborda sobre as vantagens da utilização de blogs quando afirma que:

\begin{abstract}
Atualmente, várias são as formas de utilização dos blogs nos processos de ensino. Sob o nosso ponto de vista, a facilidade de publicação e o grande atrativo que essas páginas exercem sobre os jovens, são fatores que contribuem para essa tendência. É preciso apenas, que os professores se apropriem da linguagem e explorem com seus alunos as várias possibilidades desse novo ambiente, que pode se tornar um ambiente de aprendizagem [...]. Os blogs têm grande poder de comunicação. Alunos passam a ser autores e leitores do seu conteúdo. (ARAÚJO, 2009, p.64)
\end{abstract}

- Segundo desafio: A partir da pesquisa realizada sobre os esportes, os alunos foram à prática e utilizaram o kit de robótica Atto Educacional ${ }^{\circledR}$ para elaborarem os jogos. Neste momento, perceberam que para cumprir o desafio, precisariam fazer alterações em seus projetos iniciais e até mesmo a troca de esporte base para o respectivo jogo. Essa ação é considerada importante para a percepção de que os erros fazem parte do processo de construção do conhecimento. Os jogos criados foram praticados por alunos do Ensino fundamental I, os quais estão descritos a seguir:

* Lançador de aviões de papel: criado a partir do esporte "arco e flecha". Foi construída uma pista com marcações de distância e ponto de partida. Vencia o jogador que lançasse o avião de papel mais longe, dentro da pista projetada.

* Fast bike: o esporte base para o jogo foi "ciclismo mountain bike". Os alunos montaram dois triciclos que, puxados com barbantes, deveriam cumprir uma pista com obstáculos em menos tempo. Neste jogo, os alunos alteraram os obstáculos previamente pensados, para que houvesse sucesso no jogo criado.

* Bola no cesto: baseado no esporte basquete. O objetivo foi acertar a bolinha no cesto. Os alunos que montaram este jogo refletiram sobre a atividade e concluíram que a jogabilidade não foi adequada à idade das crianças, pois foram marcados apenas 6 pontos, em 50 jogadas. Explicou o aluno 3, criador do jogo: "era necessário concentração e controle da força aplicada ao trampolim, difícil para crianças de 9 anos".

* Hóquei de mesa: baseado no esporte "hóquei sobre a grama". Cada jogador tinha um bastão e deveria empurrar a bolinha ao gol, desviando de obstáculos construídos sobre uma mesa.

Após as oficinas, as duplas se reuniram para discutir sobre todo o processo de pesquisa, construção e aplicação dos jogos, bem como produziram uma síntese, com as alterações necessárias e suas opiniões sobre o desenvolvimento do desafio. Como cita Pérez Gómez (2015, p. 116) “estabelecer a ponte entre a base anterior já construída pelo próprio sujeito e o horizonte de possibilidades aberto pelos intercâmbios educacionais é o propósito da metodologia didática." 
VIII Congresso Brasileiro de Informática na Educação (CBIE 2019)

Anais do XXV Workshop de Informática na Escola (WIE 2019)

- Terceiro desafio: Após as pesquisas no laboratório de informática, os alunos construíram os seguintes protótipos: gira-gira, helicóptero, carrinho e roda-gigante. Todos com movimentos automatizados através de alimentação externa, como pilhas e baterias.

Durante o evento escolar "Olimpíada do Conhecimento", o Grupo foi responsável por uma das oficinas, onde cada aluno mostrou seu protótipo automatizado para os alunos visitantes, explicando sobre sua montagem e funcionalidade, realizando o papel de professores, oportunizando aos ouvintes o manuseio das peças e orientando a montagem de helicópteros e rodas-gigantes em miniatura.

O envolvimento dos alunos e a preparação para a socialização dos trabalhos demonstra que o trabalho em grupo fortalece vínculos e estimula a criatividade. Papert (1994, p.161) diz que a "oportunidade para a fantasia abre a porta para um sentimento de intimidade com o trabalho e proporciona um vislumbre de como o lado emocional do relacionamento das crianças com a ciência e a tecnologia poderia ser muito diferente do que é na tradicional Escola."

\subsubsection{Desafios para o segundo semestre de 2016}

- Primeiro desafio: Foram criados três objetos programados com Arduíno. O primeiro objeto tratou da programação de sensores de luminosidade, cuja resposta à falta de luz era o soar do buzzer e o piscar das leds. Assim que o sensor recebia a luz novamente, as leds paravam de piscar e o som de soar.

A roda-gigante, ligada a um potenciômetro, foi o segundo objeto deste desafio. Este artefato analógico foi ligado a um motor através da placa de interface programável. Os alunos realizaram a programação da roda-gigante, onde a velocidade da mesma era diminuída ao se aproximar do desembarque de passageiros e aumentada gradativamente em seguida. Em consonância, luzes de led vermelha, amarela e verde foram também programadas.

O último objeto deste desafio foi a programação de um carrinho com sensor de distância que, através da programação, ao encontrar um obstáculo, desviava do mesmo acionando a ré, a direita e esquerda. Conectado por uma alimentação externa, o carrinho dos alunos pôde andar e desviar dos obstáculos com pleno funcionamento.

- Segundo desafio: Nessa atividade, os alunos foram os professores da aula prática sobre velocidade média, na turma do nono ano, realizando a demonstração do carrinho automatizado, no desafio anterior.

Durante a aula, a turma realizou os cálculos de velocidade média, construiu gráficos, analisou os valores, socializou as informações e concluiu acerca da atividade realizada, apontando qual protótipo foi o mais rápido, o mais lento e a aceleração obtida nos movimentos. Este desafio foi motivador, pois, utilizar atividades práticas para aplicação de conceitos científicos a aula se tornou mais atrativa e de fácil compreensão, além de desenvolver a oralidade, o senso de responsabilidade, a autoconfiança e a autoestima dos alunos no papel de multiplicadores dos conhecimentos adquiridos durante o projeto de robótica. Tal afirmação corrobora com Moraes (2010) quando afirma que:

O aprendiz torna-se agente de seu próprio conhecimento e constrói, por si só, todo o processo de aprendizagem. A partir da interação com a realidade o sujeito em aprendizagem, busca a solução e pode avaliar, se sua ação foi correta diante da reflexão que o aprende a aprender. (MORAES, 2010, p. 18) 
VIII Congresso Brasileiro de Informática na Educação (CBIE 2019)

Anais do XXV Workshop de Informática na Escola (WIE 2019)

Para concluir as atividades, foi realizada uma visita técnica ao grupo especializado em robótica WickedBotz, pertencente a Pontifícia Universidade Católica (PUC), da cidade de Jaraguá do Sul, na qual os alunos conheceram sua infraestrutura e visualizaram os robôs e o drone do grupo. Foi possível observar o interesse e o deslumbramento dos alunos em relação ao vasto campo do conhecimento que ainda poderia ser explorado. $\mathrm{O}$ contato com a infraestrutura de laboratórios e materiais de uma Universidade motivou os alunos e contribuiu para a escolha profissional de alguns membros do grupo.

\subsection{Avaliação das aprendizagens}

A avaliação do processo de aprendizagem ocorreu durante todo o desenvolvimento dos desafios, através da observação da ajuda mútua entre os alunos, a exemplo da indicação de sites de pesquisa durante a montagem dos protótipos, da busca de baterias e motores para o colega ou dos palpites ao defender seu trabalho. Tal constatação corrobora com Miranda e Suanno (2009), quando abordam que:

Na robótica aplicada à educação, o importante é o processo, o desenrolar dos trabalhos e não o resultado por si só. É imprescindível explorar todas as possibilidades, buscando o aprendizado por meio da reflexão individual e da interação em grupo e, em seguida, propor alternativas para a solução de situações-problemas por meio do aprimoramento de montagens, ideias e abordagens. (MIRANDA E SUANNO, 2009, p.3)

Os alunos estavam constantemente analisando os trabalhos e propondo soluções para os problemas emergentes, percebendo que o trabalho em equipe é fundamental para o sucesso de um projeto e entendendo que o erro faz parte do processo de construção do conhecimento, envolvendo procedimentos de reflexão, ação e depuração.

Segundo Miranda e Suanno (2009), a robótica educacional:

Oferece um ambiente diferenciado de interação entre os alunos, além de uma oportunidade de reunir ideias e buscar soluções para uma situação-problema em conjunto. Também gera discussões e conflitos que precisam ser resolvidos para que a solução apareça, permite aprender melhor a ouvir e a expor as ideias de cada aluno e mostra que o erro pode ser um primeiro passo para o acerto. (MIRANDA E SUANNO, 2009, p.4)

Além dos apontamentos feitos pelos autores, podemos acrescentar que a robótica educacional proporcionou a curiosidade pela investigação, despertou a criatividade dos alunos, desenvolveu a coordenação motora, o companheirismo, a observação, a oratória, a autoconfiança e a autoestima, como se observa ao analisar a categorização dos depoimentos, segundo a tabela 2.

Tabela 2. Categorização dos depoimentos dos alunos

\begin{tabular}{|c|l|}
\hline $\begin{array}{c}\text { Categorização } \\
\text { da importância } \\
\text { das oficinas }\end{array}$ & \multicolumn{1}{c|}{ Depoimentos } \\
\hline \multirow{2}{*}{ Experimentação } & $\begin{array}{l}\text { "O que achei mais importante foi o aprendizado e um pouco mais } \\
\text { de experiência com os motores, que são da parte elétrica e o } \\
\text { manuseio das peças." }\end{array}$ \\
\cline { 2 - 2 } & $\begin{array}{l}\text { "Ficou mais fácil entender como calculamos a velocidade média } \\
\text { na prática." }\end{array}$ \\
\hline
\end{tabular}


VIII Congresso Brasileiro de Informática na Educação (CBIE 2019)

Anais do XXV Workshop de Informática na Escola (WIE 2019)

\begin{tabular}{|c|c|}
\hline Desafios & $\begin{array}{l}\text { "Tive dificuldade em trabalhar com a roda-gigante em tamanho } \\
\text { pequeno, por esse motivo resolvi ampliá-la. No início, a montagem } \\
\text { foi complicada, pois, não tinha ideia de como faria para ligar } \\
\text { motor à roda-gigante." }\end{array}$ \\
\hline \multirow{3}{*}{$\begin{array}{l}\text { Troca de papéis: } \\
\text { aluno como } \\
\text { orientador }\end{array}$} & $\begin{array}{l}\text { Essa experiência foi legal e produtiva, percebemos que os alunos } \\
\text { gostaram da montagem e do contato com as peças da robótica e } \\
\text { acharam a dificuldade para montar excitante." (referente ao } \\
\text { evento "Olimpíada do Conhecimento) }\end{array}$ \\
\hline & $\begin{array}{l}\text { "Esse projeto foi muito divertido, porém, orientar os alunos } \\
\text { durante o jogo foi exaustivo, mas serviu de experiência, com as } \\
\text { crianças e com o manuseio das peças." }\end{array}$ \\
\hline & $\begin{array}{l}\text { "Adorei a aula prática de física, um colega nosso explicando } \\
\text { tudo." }\end{array}$ \\
\hline Aprendizado & $\begin{array}{l}\text { "Concluímos que o primeiro e o segundo projetos foram } \\
\text { estimulantes para que continuássemos querendo aprender cada } \\
\text { vez mais na robótica." }\end{array}$ \\
\hline
\end{tabular}

\section{Considerações Finais}

Ao analisar os depoimentos dos alunos podemos perceber que muitas contribuições ocorreram durante o desenvolvimento do projeto. Dentre elas, chamamos atenção para a mudança de papéis dos sujeitos, observamos os professores interagindo como facilitadores do processo, apontando desafios a serem superados pelos alunos, que tiveram autonomia e protagonismo para resolverem os problemas. Da mesma maneira, identificamos a utilização dos conhecimentos prévios, o desenvolvimento da capacidade de pesquisa e entusiasmo pela descoberta, assim como aponta Fiori et al (2014) que "repassar o conhecimento das áreas tecnológicas e incentivar seu uso pode trazer resultados esperados por qualquer docente: a participação, desenvolvimento do pensamento crítico e o aprendizado de seu aluno".

Observamos, por conseguinte, que as ações do projeto de robótica, propiciaram aos alunos: capacidade de trabalhar em grupo; capacidade de pensar múltiplas alternativas para a solução de um problema; habilidades e competências ligadas à lógica, noção espacial, pensamento matemático, organização e planejamento de projeto; realizar o desenvolvimento de projeto a partir de conhecimentos diversos; promover a interdisciplinaridade. Em consonância com o que diz Cruz et al (2007) sobre a presença da robótica em sala "provê um ambiente de aprendizagem interdisciplinar que contribui para o desenvolvimento da criatividade e pensamento crítico dos aprendizes, forjando as habilidades necessárias para estruturar pesquisas e resolver problemas concretos."

Os êxitos apontados estão de acordo com as competências ${ }^{3}$ gerais da Educação Básica, contidos na BNCC (BRASIL, 2017), especificamente 2, 4, 5 e 10: "exercitar a

\footnotetext{
${ }^{3} \mathrm{Na} \mathrm{BNCC}$, competência é definida como a mobilização de conhecimentos (conceitos e procedimentos), habilidades (práticas, cognitivas e socioemocionais), atitudes e valores para resolver demandas complexas da vida cotidiana, do pleno exercício da cidadania e do mundo do trabalho.
} 
VIII Congresso Brasileiro de Informática na Educação (CBIE 2019)

Anais do XXV Workshop de Informática na Escola (WIE 2019)

curiosidade intelectual; utilizar diferentes linguagens; compreender, utilizar e criar tecnologias digitais de informação e comunicação; agir pessoal e coletivamente com autonomia, responsabilidade, flexibilidade, resiliência e determinação".

Desse modo, do ponto de vista legal, a robótica educacional pode ser considerada como uma ferramenta que contribuiu para o desenvolvimento da autonomia do aluno, através de práticas de pesquisa, experimentação, modelagem, construção e abstração. Tais ações permitiram aos alunos imprimir seu próprio ritmo de aprendizagem, de acordo com seus interesses, transformando o caminho entre erros ${ }^{4} \mathrm{e}$ acertos, em um ciclo valoroso de aprendizagem através da depuração. Para tanto, foi fundamental envolver duas dimensões importantes: liberdade e responsabilidade, as quais demandaram que o papel do professor e o papel do aluno fossem ressignificados.

É válido dizer que a robótica aplicada em uma escola pública traz benefícios ao processo ensino-aprendizagem, desde o protagonismo juvenil até a ressignificação de papéis de professores e alunos, proporcionando o desenvolvimento de habilidades e competências que transcendem a delimitação das disciplinas escolares. Como sugestão para trabalhos futuros, indica-se a aplicação desta metodologia com um número maior de alunos, para análise dos seus benefícios e desafios.

\section{Referências}

ARAÚJO, Michele Menghetti Ugulino de. Potencialidades do uso do blog em educação. Dissertação de Mestrado. Universidade Federal do Rio Grande do Norte. Centro de Ciências Sociais Aplicadas. Programa de Pós-Graduação em Educação. Natal, 2009.

BARDIN, Laurence. Análise de conteúdo. São Paulo: Edições 70, 2011.

BRASIL, Base Nacional Comum Curricular (BNCC). Educação é a Base. Brasília, MEC/CONSED/UNDIME, 2017. Disponível em: < http://basenacionalcomum.mec.gov.br/a-base>. Acesso em: 03 de mai. 2019.

CRUZ, Sérgio Manuel Serra da et al. Hajime: O relato de um experimento em robótica educacional de baixo custo. (Simpósio Brasileiro de Informática na Educação SBIE), p. 176-179, nov. 2007. Disponível em: <https://www.brie.org/pub/index.php/sbie/article/view/650>. Acesso em: 07 set. 2019.

CHIOFI, Luiz Carlos; OLIVEIRA, Marta Regina Furlan de Oliveira. O Uso das Tecnologias Educacionais Como Ferramenta Didática no Processo de Ensino e Aprendizagem. III Jornada Didática: Desafios Para a Docência. II Seminário de pesquisa do CEMAD. Universidade Estadual de Londrina, Londrina - PR, 2014.

FIORIO, Rosaine et al. Uma experiência prática da inserção da robótica e seus beneficios como ferramenta educativa em escolas públicas. (Simpósio Brasileiro de Informática na Educação - SBIE), p. 1223 - 1232, nov. 2014. Disponível em: $<$ https://www.br-ie.org/pub/index.php/sbie/article/view/3070> $>$. Acesso em: 06 de set 2019 .

FREIRE, Paulo. Pedagogia do oprimido. $10^{\text {a }}$ ed. Rio de Janeiro, RJ: Paz e Terra, 1981.

\footnotetext{
${ }^{4}$ Para este trabalho, entendemos erro, não como uma falha passível de repressão, mas como o ponto de partida para novas aprendizagens.
} 
VIII Congresso Brasileiro de Informática na Educação (CBIE 2019)

Anais do XXV Workshop de Informática na Escola (WIE 2019)

LÜDKE, Menga.; ANDRÉ, Marli E. D. A. Pesquisa em educação: abordagens qualitativas. São Paulo: EPU, 1986.

MENEZES, Ebenezer Takuno de; SANTOS, Thais Helena dos. Verbete robótica educacional. Dicionário Interativo da Educação Brasileira - Educabrasil. São Paulo: Midiamix, 2015. Disponível em: $<$ https://www.educabrasil.com.br/roboticaeducacional/>. Acesso em: 03 de mai. 2019.

MIRANDA, Juliano Rodrigues; SUANNO, Marilza V. R. Robótica Pedagógica: prática pedagógica inovadora. IX Congresso Nacional de Educação (EDUCERE); III Encontro Sul Brasileiro de Psicopedagogia; Paraná: PUCPR, 2009. Disponível em: < https://www.pucpr.br/eventos/educere/educere2009/anais/pdf/3534 1980.pdf> Acesso em: 03 de mai. 2019.

MORAES, Maritza Costa. Robótica Educacional: Socializando e produzindo conhecimentos matemáticos. Dissertação de Mestrado. Universidade Federal do Rio Grande - UFRG. 2010.

PAPERT, Seymour. A máquina das crianças: repensando a escola na era da informática. Artes Médicas. Porto Alegre: 1994.

PÉREZ GÓMEZ, Ángel I.: A educação na era digital: escola educativa. Porto Alegre: Penso, 2015.

RAABE, André e GOMES, Eduardo Borges, 2018. Maker: uma nova abordagem para tecnologia na educação. Disponível em: <https://tecedu.pro.br/wpcontent/uploads/2018/09/Art1-vol.26-EdicaoTematicaVIII-Setembro2018.pdf> . Acesso em: 03 de mai. 2019.

ZILLI, Silvana do Rocio. A Robótica Educacional no Ensino Fundamental: Perspectivas e Prática. 89 f. Dissertação de Mestrado em Engenharia de Produção Programa de Pós-Graduação em Engenharia de Produção, UFSC, Florianópolis, 2004. 